\title{
Human NCU-G I can function as a transcription factor and as a nuclear receptor co-activator
} Knut R Steffensen ${ }^{2}$, Mariam Bouzga ${ }^{1}$, Frode Skjeldal ${ }^{1}$, Cecilie Kasi ${ }^{1}$, Almira Karahasan ${ }^{1}$, Vilborg Matre ${ }^{1}$, Oddmund Bakke ${ }^{1}$, Sylvain Guérin ${ }^{3}$ and Winnie Eskild*1

Address: ${ }^{1}$ Department of Molecular Biosciences, University of Oslo, Norway, ${ }^{2}$ Department of Biosciences and Nutrition, Karolinska Institutet, Huddinge, Sweden and ${ }^{3}$ Oncology and Molecular Endocrinology Research Center, CHUL, Centre Hospitalier Universitaire de Québec and Laval University, Québec, Canada

Email: Knut R Steffensen - knut.steffensen@biosci.ki.se; Mariam Bouzga - mariam.bouzga@medisin.uio.no;

Frode Skjeldal - frode.skjeldal@imbv.uio.no; Cecilie Kasi - cecilie.kasi@imbv.uio.no; Almira Karahasan - almira.karahasan@medisin.uio.no; Vilborg Matre - vilborg.matre@imbv.uio.no; Oddmund Bakke - oddmund.bakke@imbv.uio.no; Sylvain Guérin - sylvain.guerin@crchul.ulaval.ca; Winnie Eskild* - winnie.eskild@imbv.uio.no

* Corresponding author

Published: 16 November 2007

BMC Molecular Biology 2007, 8:106 doi:10.1 186/1471-2199-8-106
Received: 30 April 2007

Accepted: 16 November 2007

This article is available from: http://www.biomedcentral.com//47/-2199/8/106

(c) 2007 Steffensen et al; licensee BioMed Central Ltd.

This is an Open Access article distributed under the terms of the Creative Commons Attribution License (http://creativecommons.org/licenses/by/2.0), which permits unrestricted use, distribution, and reproduction in any medium, provided the original work is properly cited.

\begin{abstract}
Background: Novel, uncharacterised proteins represent a challenge in biochemistry and molecular biology. In this report we present an initial functional characterization of human kidney predominant protein, NCU-GI.

Results: NCU-GI was found to be a highly conserved nuclear protein rich in proline with a molecular weight of approximately $44 \mathrm{kDa}$. It is localized on chromosome I and consists of 6 exons. Analysis of the amino acid sequence revealed no known transcription activation domains or DNA binding regions, however, four nuclear receptor boxes (LXXLL), and four SH3-interaction motives in addition to numerous potential phosphorylation sites were found. Two nuclear export signals were identified, but no nuclear localization signal. In man, NCU-GI was found to be widely expressed at the mRNA level with especially high levels detected in prostate, liver and kidney. Electrophoretic mobility shift analysis showed specific binding of NCU-GI to an oligonucleotide representing the footprint I element of the human cellular retinol-binding protein I gene promoter. NCU-GI was found to activate transcription from this promoter and required presence of the footprint I element. In transiently transfected Drosophila Schneider S2 cells, we demonstrated that NCU-GI functions as a co-activator for ligand-activated PPAR-alpha, resulting in an increased expression of a CAT reporter gene under control of the peroxisome proliferatoractivated receptor-alpha responsive acyl-CoA oxidase promoter.
\end{abstract}

Conclusion: We propose that NCU-GI is a dual-function protein capable of functioning as a transcription factor as well as a nuclear receptor co-activator. 


\section{Background}

Vitamin A is required for proper cell growth, differentiation and function. These processes depend on expression of appropriate genes at the right time and place, and in correct amounts. The biological activity with regard to vitamin A control of gene expression is carried out by retinoic acid (all-trans isomer or 9-cis isomer), the ligand for retinoic acid receptors (RARs and RXRs), which are members of the nuclear receptor superfamily of ligandactivated transcription factors [1,2]. Malfunction of vitamin A regulated genes have been described in various cancer types [3-5]. Some human carcinomas were shown to be affected in this manner due to reduced levels of RAR$\beta_{2}$, a retinoic acid receptor isoform involved in negative growth regulation [6].

In addition to suboptimal expression or malfunctioning of retinoic acid receptors, reduced retinoic acid (RA) activity may also occur because RA is not available. Expression of some retinoic acid receptors is itself vitamin A dependent, hence the availability of RA becomes crucial. Most cells depend on conversion of retinol to RA to satisfy their needs for this ligand [7]. Retinol ( $\mathrm{ROH})$ is taken up from circulating retinol-binding protein (RBP) or released from intracellular storage of retinylester and transferred to cellular retinol-binding protein type 1 (CRBP1) which regulates its metabolism. In addition to regulating cellular uptake of $\mathrm{ROH}, \mathrm{CRBP} 1$ presents $\mathrm{ROH}$ to lecithin:retinol acyl transferase (LRAT) for esterification and storage in lipid droplets in the cell cytoplasm or interacts with oxidizing enzymes which convert ROH to RA. Hence, CRBP1 plays an essential role in the regulation of vitamin A controlled genes and maintenance of proper cell health.

In contrast to previous concepts of CRBP1 as an inert chaperone for ROH, CRBP1 is now viewed as an active participant in vitamin A metabolism [8-10]. The general understanding of the mechanisms regulating CRBP1 expression and function, however, is not very comprehensive. It has been reported that retinoids, lipids and serum factors increase the expression of CRBP1, whereas CAMP and glucocorticoids reduce expression [11-16]. Presently it is not known whether any regulation of CRBP1 activity by way of posttranslational modification is taking place. We are working to identify regulatory mechanisms controlling CRBP1 expression by identifying novel proteins interacting with the proximal 5'-region $(-567 /+104)$ of the human CRBP1 gene. In a previous report we identified the transcription start site and seven DNA elements (FP1 FP7) which specifically bind nuclear proteins from liver, kidney and prostate [17]. Several of the DNA elements were potential binding sites for novel transcription factors. Here we report the identification and characterisation of one such protein, NCU-G1, which interacts specifically with FP1 and stimulates transcription from the CRBP1 promoter. In addition, NCU-G1 functions as a nuclear receptor co-activator by stimulating the transcriptional activity of peroxisome proliferator-activated receptor-alpha (PPAR-alpha).

\section{Results \\ Cloning of human NCU-GI}

Previous studies of the hCRBP1 gene promoter identified a DNA-element $(\mathrm{FP} 1,+66 /+96)$ that comprises target sites for both the nuclear factor 1 (NF1) and specificity protein 1 (Sp1) transcription factors [17]. Further studies, using SDS-PAGE fractionation and partial renaturation of nuclear proteins, enabled us to detect binding of two unknown proteins, designated Bp1 and Bp2, to the FP1element [18]. Bp1 and Bp2, which compete with both Sp1 and NF1 for binding to the Fp1 element, could be revealed by exploiting the fact that neither Sp1 nor NF1 renature after SDS-PAGE fractionation and hence do not bind FP1 in electrophoretic mobility shift assay (EMSA) [19].

In order to study these proteins in more detail, we used the One-Hybrid cloning strategy to clone their corresponding cDNAs from an expression library prepared from human placenta. The FP1 element was used as bait after some modifications to avoid recognition by NF1 and Sp1. Screening of the placenta expression library resulted in isolation of three unique clones one of which contained an insert of $1.7 \mathrm{~kb}$. DNA sequencing of this clone revealed an open reading frame of 1221 base pairs yielding a protein of 406 amino acids (figure 1A). Blast analysis identified it as kidney predominant protein, alias NCUG1 or C1orf85 homologous to the previously published mouse NCU-G1 [20]. A search of the human genome database showed that NCU-G1 is located on chromosome $1,1 \mathrm{q} 23.1$, locus 112770 , and has an open reading frame spanning 6 exons. No human homologues were identified, indicating that NCU-G1 is unique.

Comparison with NCBI GenBank [21] showed a number of previously submitted sequences corresponding to human NCU-G1 (GenBank: NM 144580, BC018757, BC011575), however, no functional characterization of this protein has been reported. Database searches including other species revealed that mammals, birds, frogs and certain mosquitos all have an NCU-G1 gene (figure 1A), whereas Drosophila melanogaster does not. In rodents (mouse, rat) the open reading frame (ORF) is 404 amino acids. The human gene has inserted a leucine after amino acid 52 and a lysine after amino acid 139. The NCU-G1 gene appears to be highly conserved. Complete conservation of more than $25 \%$ of amino acids is seen from mosquito to man, and conservative conservation is found in all available sequences from worm to man. At the amino acid level, homologies between man/chimpanzee is 

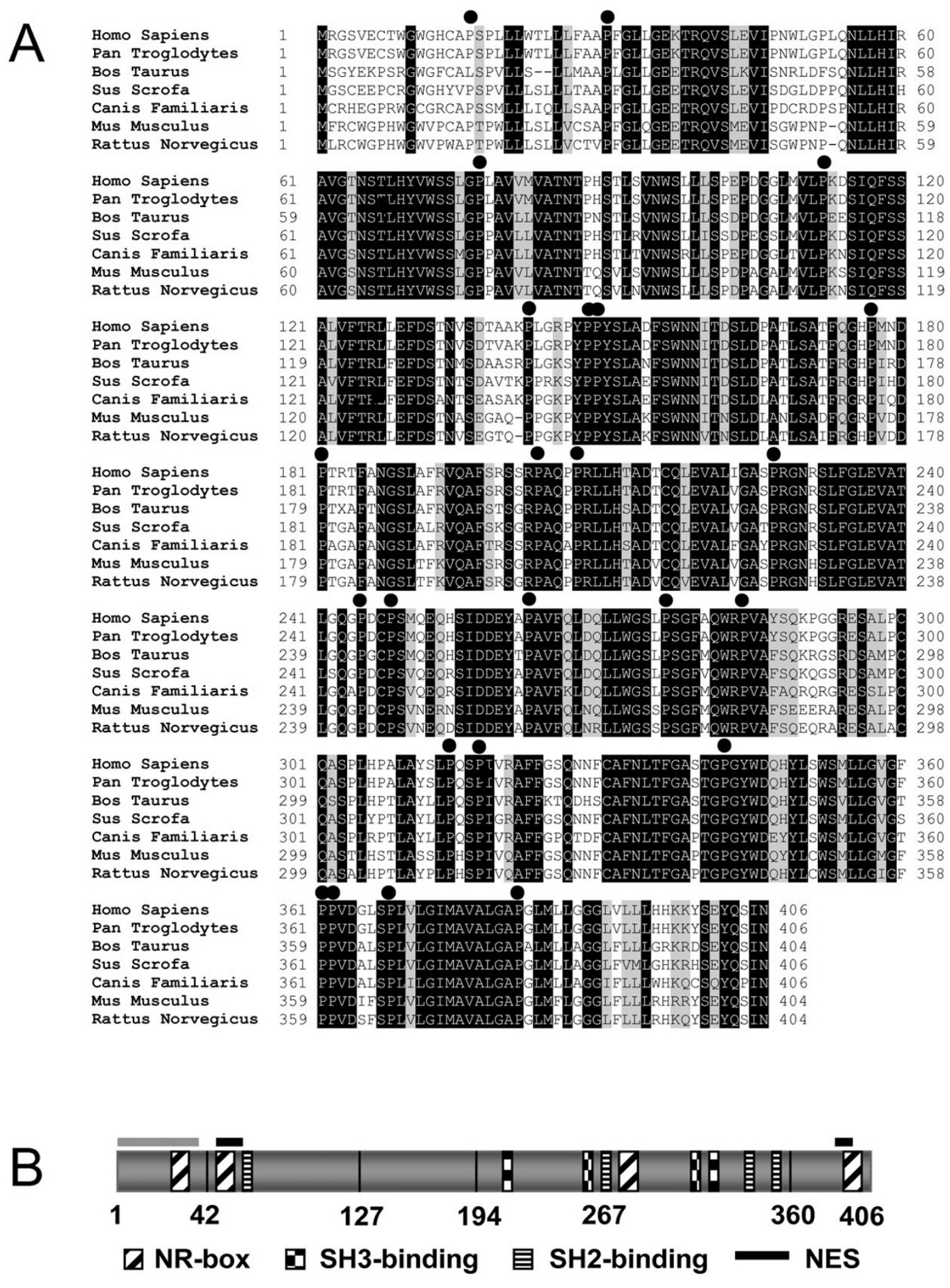

\section{Signal peptide}

Figure I

Analysis of the NCU-GI amino acid sequence. Panel A: Comparison of deduced NCU-GI amino acid sequences from various species. Totally conserved amino acids are shown against a black background. Highly conserved amino acids are shown against a grey background. The positions of conserved prolines are marked with black bullets. Panel B: Potential functional motifs in human NCU-GI. 
$99.8 \%$, man/rat $79 \%$, man/mouse $79 \%$ and rat/mouse $82 \%$. Figure $1 \mathrm{~A}$ shows that there are highly conserved regions and distinct areas where variations can occur. The protein has a high content of proline $(9.1 \%)$ but no specific proline-rich regions. However, the proline positions are well conserved.

To search for information on the structure and function of the NCU-G1 gene product, a variety of data mining tools were used. NCU-G1 has a predicted MW of $43.8 \mathrm{kDa}$ and an acidic pI of 6.1 [22]. The molecular weight was verified by Western analysis using a polyclonal antibody which we raised against a 15 -amino acid peptide covering the C-terminal sequence (see below, figure 2A). No homologies to known DNA-binding motifs, transcription activation domains or regions with enzymatic activity were found. Somewhat surprising, NCU-G1 has four NR-boxes with the LXXLL signature sequence $[23,24]$. Such NR-boxes are found in a number of transcriptional co-activators, such as the p160-family of co-activators for which the LXXLL sequences are characteristic $[25,26]$. The presence of an NR-box has been determined as necessary and sufficient for interaction with nuclear receptors, although both recruitment and effect on transcription are influenced by other factors such as the sequences flanking the NR-box, the ligand types of the nuclear receptor itself and the DNA response elements present on the target genes. As shown in figure $1 \mathrm{~B}$, the LXXLL-motifs were distributed over the entire protein. The first NR-box (aa 21-25) is conserved in all NCU-G1 sequences from man to frog. The second NRbox (aa 53-57) is unusual being preceded by a proline residue. This NR-box is found only in the NCU-G1 protein from man and chimpanzee. One of the inserted amino acids (aa 53), making up part of the difference between rodents and man, is the first leucine in NR-box no. 2 of man. The third NR-box (aa 267-271) is present in all mammals while the fourth NR-box (aa 390-394) is found in all mammals except in pig.

Four potential Src-homology 3 (SH3) interacting domains with the signature sequence PXXP were also identified in NCU-G1 (figure 1B). According to Cesareni et al. [27] motif no. 1 (aa 203-206) is a class II motif, whereas motif no. 4 (aa 298-301) belongs to class I. As shown for the modulator of non-genomic action of estrogen receptor (MNAR), these motifs may bind $\mathrm{SH} 3$ domains in c-Src, stabilizing its interaction with a nuclear receptor and leading to further activation of the ligandbound receptor [28]. It may also activate the MAP kinase signal transduction pathway.

NCU-G1 was initially identified in nuclear fractions and therefore might be expected to have a nuclear localization signal (NLS), however, analysis of the NCU-G1 sequence failed to identify any candidate sequence for an NLS [18].
In spite of this, and as figure $1 \mathrm{~B}$ indicates, two potential nuclear export signals (NES) conforming to the $\mathrm{L}\left(\mathrm{X}_{1-3}\right) \mathrm{L}\left(\mathrm{X}_{2-3}\right) \mathrm{LXL}$ formula characteristic of CRM1-mediated transport were found [29]. NES1 is localized in the Nterminus comprising amino acids 50 to 59 while NES2 is localized in the C-terminus comprising amino acids 383 to 392. Interestingly, both NES1 and NES2 overlap with an NR-box, no. 2 and no. 4, respectively.

\section{Human NCU-GI is a nuclear protein}

Our previous studies have shown that NCU-G1 is present in nuclear extracts but we could not exclude the possibility that it may also be present in other subcellular compartments [18]. The small size of NCU-G1 would predict an ability to shuttle between cytosol and nucleus. This hypothesis was examined by analyzing nuclear and cytosolic fractions from several cell types by Western blotting.

A polyclonal antibody was raised against a peptide representing the last fifteen amino acids in the C-terminus of NCU-G1. Its specificity was verified by Western analysis of transiently expressed NCU-G1 in Drosophila Schneider S2 cells which do not express this protein. The predicted size of NCU-G1 is $43.8 \mathrm{kDa}$. As shown in figure 2 (panel A, lane 6) a protein of approximately $45 \mathrm{kDa}$ in size is detected with this antibody. In contrast, a transiently expressed truncated version of NCU-G1 lacking exon 6 comprising the C-terminal end of the protein could not be detected (figure 2A, lane 7). Using this antibody, we found that NCU-G1 is primarily localized in the nuclei of JEG3, RPE and 293 cells (figure 2B; lanes 2, 4 and 6, respectively). The traces of NCU-G1 detected in the cytosol were probably due to leakage from the nuclei during preparation. In order to test this assumption, the membranes were stripped and analyzed with an antibody against Sp1 as a marker of nuclear proteins. Figure 2C shows that some Sp1 is found in the cytosolic fractions, supporting the notion that partial nuclear rupture during preparation may account for the NCU-G1 detected in cytosol.

\section{Human NCU-GI binds specifically to the FPI- oligonucleotide}

The initial identification of NCU-G1 was based on its ability to bind FP1 in EMSA. In order to show that our cloned NCU-G1 represents the proteins we set out to clone, its ability to bind DNA was studied. Figure 3 shows complex formation in EMSA between ${ }^{32}$ P-labeled FP1-oligonucleotide and GST-NCU-G1 fusion protein recombinantly expressed in E. coli. A major band (lane 2) shows specific binding which is inhibited in the presence of 50-fold molar excess of unlabeled FP1 oligonucleotide (lane 3). Unlabeled AP1-, Sp1- or NF1-oligonucleotides at 50-fold molar excess (lane 4, 5 and 6, respectively) are unable to 

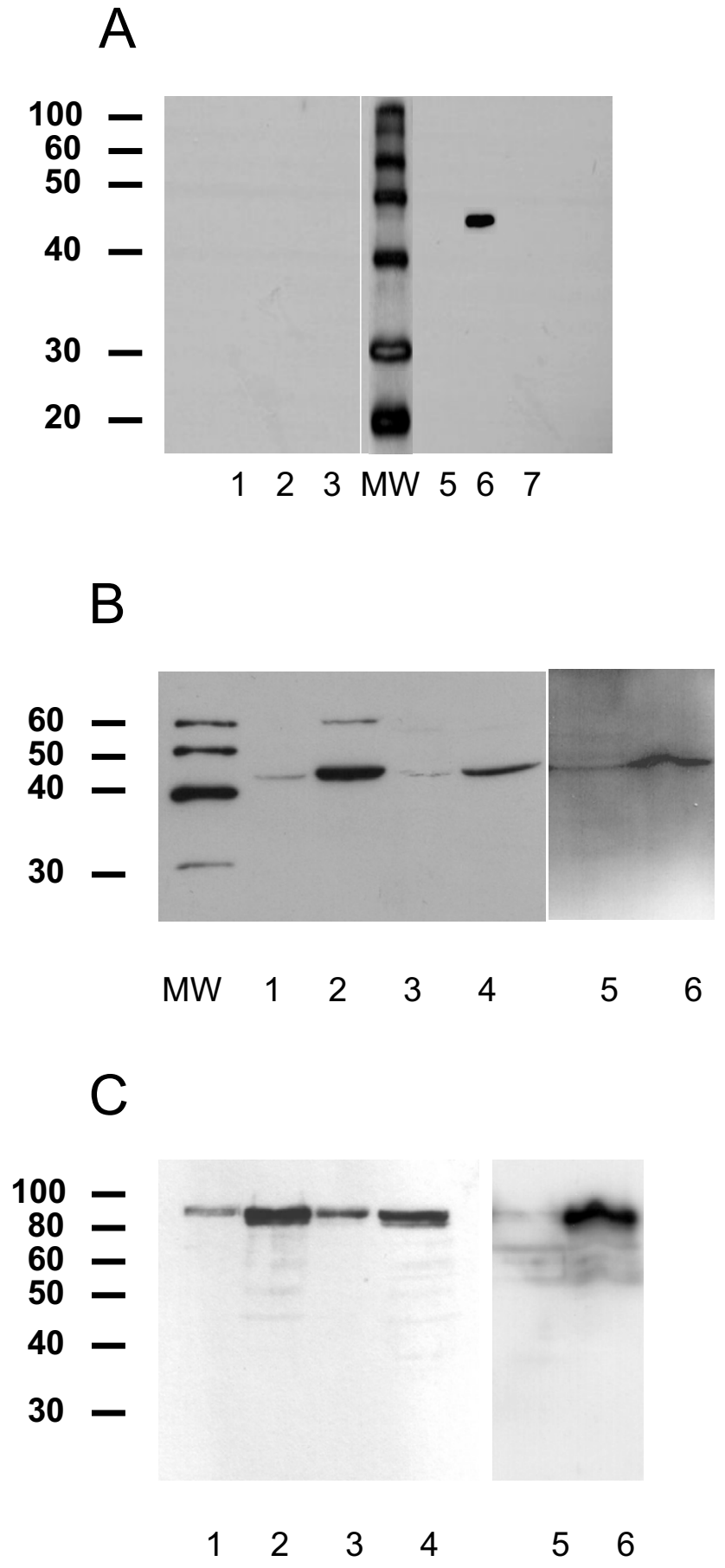

Figure 2

Endogenous NCU-GI is a nuclear protein. Panel A: S2 cells were transfected with expression vectors for hNCU-G I (pAc-NCU-GI) or its truncated version pAc-hNCU-GI $(\Delta$ exon 6$)$. Whole cell extracts $(20 \mu g / l a n e)$ were analyzed by Western blotting using preimmune serum (lanes I to 3) or an antiserum raised against a C-terminal I 5 amino acid peptide (lanes 5 to 7). Lane I and 5: control, untreated S2 cells, lane 2 and 6: S2 cells expressing hNCU-GI, lane 3 and 7: S2 cells expressing hNCU-GI $(\Delta$ exon6). Panel B: Cytoplasmic and nuclear extracts $(20 \mu \mathrm{g} /$ lane $)$ from JEG3, RPE and 293 cells were size-fractionated on 10\% SDS-PAGE gels and analyzed by Western blotting using NCU-GI antiserum. Lane I: JEG3 cytosol, lane 2: JEG3 nuclear extract, lane 3: RPE cytosol, lane 4: RPE nuclear extract, lane 5: 293 cytosol, lane 6: 293 nuclear extract. Panel C: The membranes used in panel B were stripped and analyzed with an antibody against Spl. 


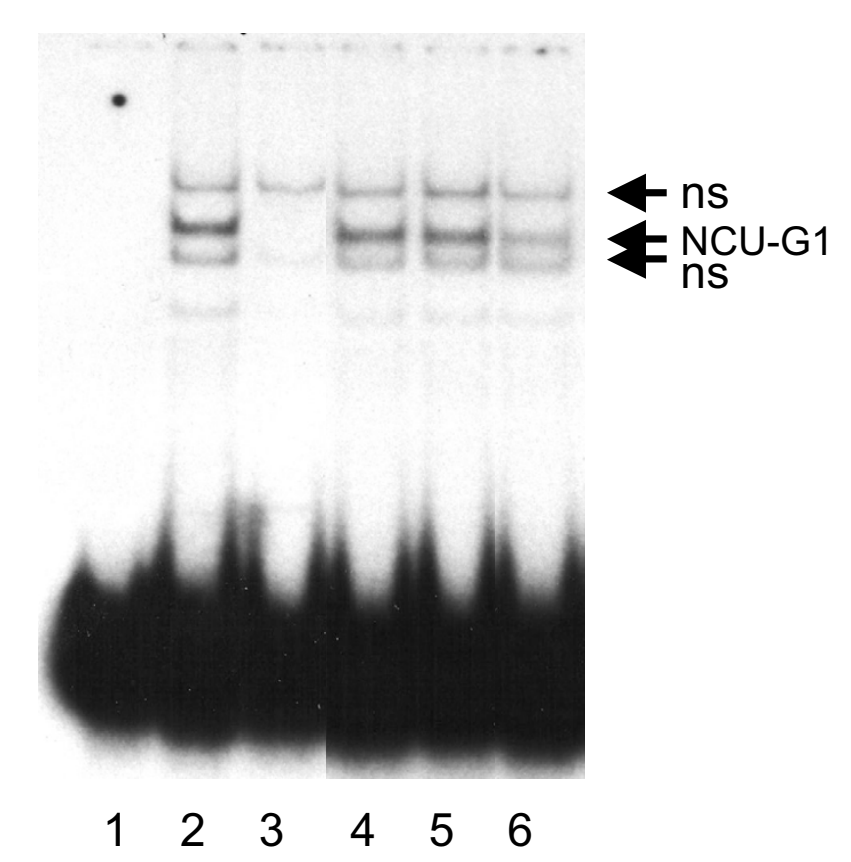

Figure 3

Human NCU-G I binds to the FPI-element of the CRBPI promoter. NCU-GI was expressed as a fusion protein with GST in E. coli and purified. Interaction between GST-NCU-GI and radiolabeled FPI-oligonucleotide was analysed by EMSA. Lane I shows ${ }^{32}$ P-labeled FPI oligonucleotide (control). Lane 2 shows complex formation between GSTNCU-GI and 32P-labeled FPI oligonucleotide. Lane 3, 4, 5 and 6 show complex formation between GST-NCU-GI and ${ }^{32} \mathrm{P}$-labeled $\mathrm{FPI}$ oligonucleotide in the presence of 50 -fold molar excess of unlabeled FPI oligonucleotide, ApI oligonucleotide, Sp I oligonucleotide or NFI oligonucleotide, respectively. Ns = non-specific.

inhibit complex formation. Control GST did not bind the FP1 oligonucleotide (data not shown).

\section{Human NCU-GI stimulates transcription from the hCRBPI promoter}

The ability of NCU-G1 to interact in EMSA with the FP1element of the human CRBP1 promoter prompted us to analyse whether such interaction might entail an ability to modulate transcription. The human CRBP1 promoter ($567 /+104 \mathrm{bp}$ ) was inserted upstream of the chloramphenicol acetyl-transferase (CAT) gene in a reporter vector (pCAT3) and transiently co-transfected with an expression vector for NCU-G1 into Drosophila Schneider S2 cells (S2 cells). These cells were chosen in order to avoid interference with Sp1 and NF1 which also bind to the FP1 element of the hCRBP1 promoter. Although these cells are not mammalian, S2 cells express transcription factors similar to those found in mammalian cells, but they often do not recognize mammalian proteins or mammalian DNA consensus elements, resulting in lower background and less interference [30]. Figure 4A shows that expression of low levels of hNCU-G1 leads to a 17-fold increase of CAT expression.

In order to test whether transcriptional induction was mediated by the FP1 element, we created deletion mutants of the CRBP1 promoter controlling reporter gene expression. The expression vector (pOCAT) used in these experiments has a somewhat higher basal activity resulting in the induction by NCU-G1 appearing smaller [17]. Expression of NCU-G1 increased reporter gene expression by 7.5 -fold (fig. 4B). Deletion of FP1 from the full-length reporter construct (phCRBP1(-483/+69)OCAT) abrogated the induction of reporter gene expression by NCUG1. Removing most of the promoter region upstream of the transcription start site but leaving FP1 intact (phCRBP1 $(-20 /+104)$ OCAT) did not affect the ability of NCU-G1 to induce reporter gene expression. Again, a deletion that removes the FP1 element from this construct abolishes this induction (phCRBP $1(-20 /+69)$ OCAT). These results demonstrate that the FP1-element is an absolute requirement for NCU-G1's ability to induce reporter gene expression from the CRBP1 promoter.

In order to eliminate the possibility of any nuclear receptor (NR)-box contribution to the CRBP1 promoter controlled reporter gene expression, we created mutated versions of NCU-G1. Single or multiple NR-boxes were mutated from LXXLL to LXXAA to inhibit interaction with possible NR-box binding proteins. Figure 4C shows that mutation of one or more NR-boxes does not affect NCUG1's ability to activate reporter gene transcription from the CRBP1 promoter, confirming that the NR-boxes are not involved.

Next, we studied the effect of deleting exons or segments of NCU-G1 on its ability to control reporter gene expression from the CRBP1 promoter. Figure 4D shows that deletion of exon 6 actually potentiates NCU-G1's stimulatory effect on CAT expression. This exon comprises a stretch of hydrophobic amino acids (aa 372-394) that may be involved in attenuating NCU-G1 stimulation of CAT expression. A deletion mutant lacking just this hydrophobic region, however, did not stimulate CAT expression to the same extent. Deletion of exon 5 and 6, exon 4-6, exon 3-6 or amino acid 1-81 reduces NCU-G1 stimulatory activity to approximately $50 \%$ of that of wild-type NCU-G1. In contrast, deletion of exon 2 results in a complete loss of stimulatory activity, indicating that this region comprising amino acids $42-126$ is important for NCU-G1 activity. 

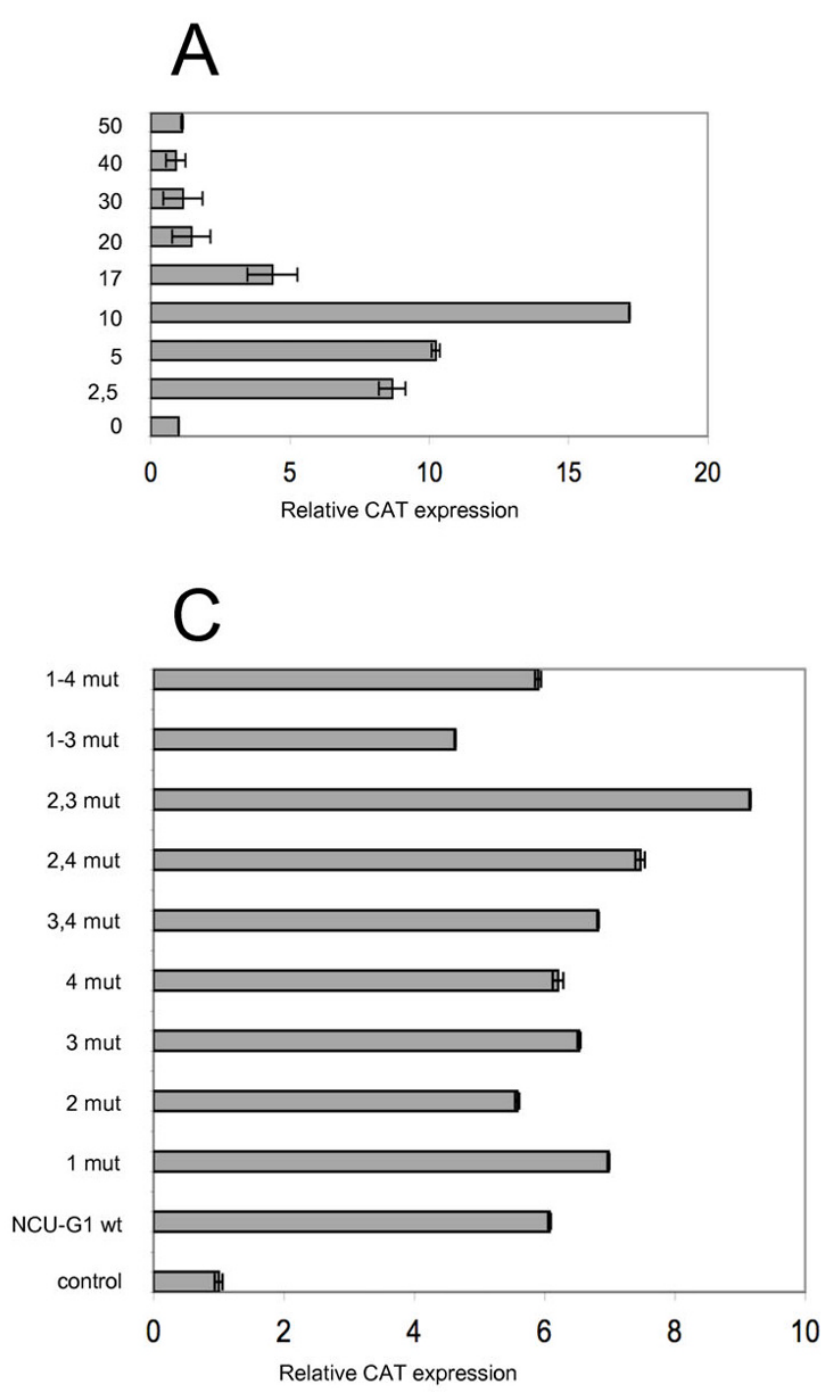
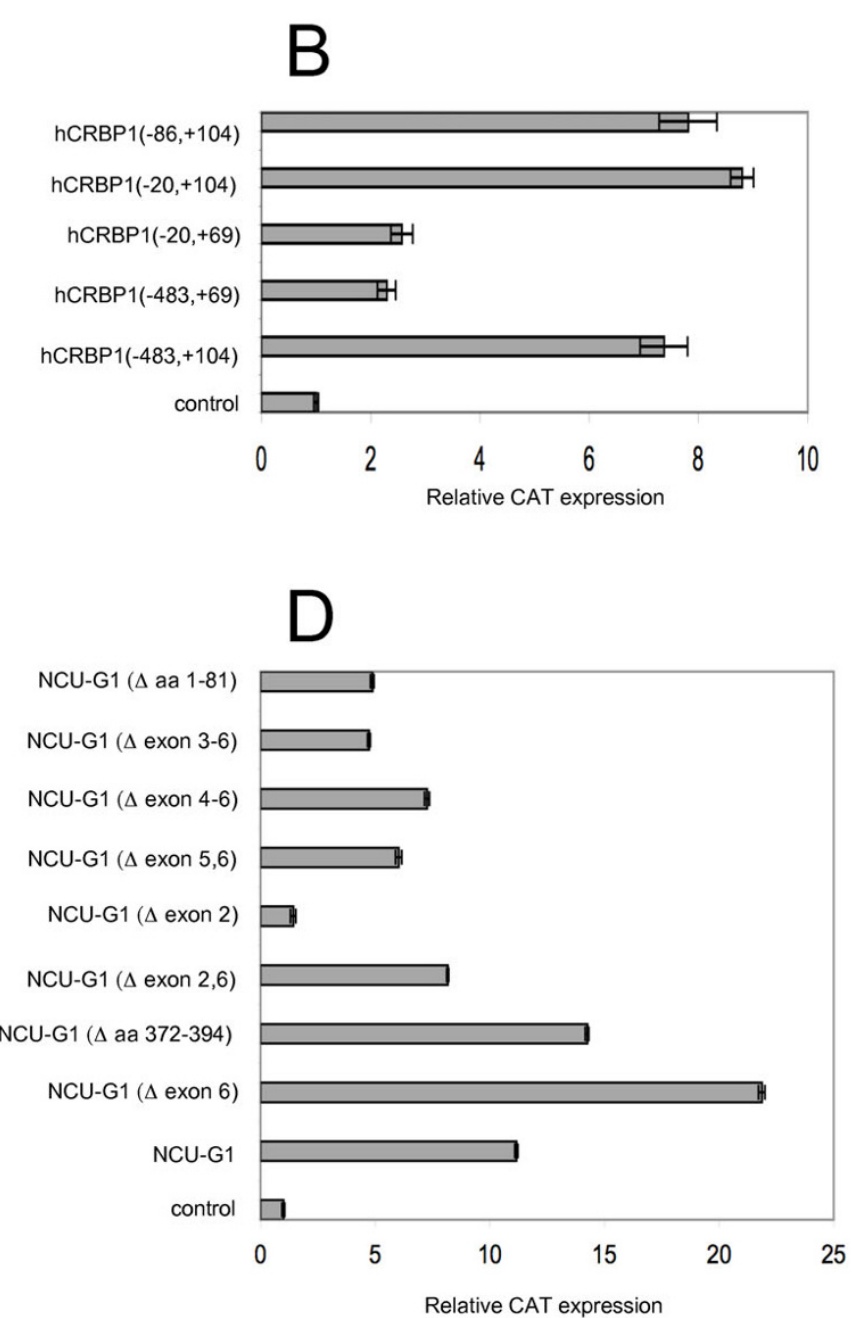

\section{Figure 4}

Human NCU-G I activates transcription from the hCRBP I promoter. Panel A: S2 cells were co-transfected with 250 ng PAc5.I/V5-His-LacZ, $350 \mathrm{ng}$ phCRBPI-CAT and increasing amounts $(2.5 \mathrm{ng}-50 \mathrm{ng})$ of pAc-hNCU-GI as shown in the figure. Panel B: S2 cells were co-transfected with $250 \mathrm{ng}$ pAc5. I/V5-His-LacZ, $350 \mathrm{ng}$ plasmid expressing CAT under the control of various fragments of the hCRBPI promoter as shown in the figure and $10 \mathrm{ng}$ PAc-hNCU-GI. Panel C: S2 cells were cotransfected with $250 \mathrm{ng}$ PAc5. I/V5-His-LacZ, $350 \mathrm{ng}$ phCRBPI-CAT and $10 \mathrm{ng}$ PAc-hNCU-G I either wild-type or carrying mutated NR-boxes as shown in the figure. Panel D: S2 cells were cotransfected with $250 \mathrm{ng}$ PAc5.I/V5-His-LacZ, $350 \mathrm{ng}$ phCRBPI-CAT and I0 ng pAc-hNCU-GI either wild-type or carrying various deletions as shown in the figure. Controls show expression of CAT in the absence of any NCU-GI. The cells were harvested $48 \mathrm{hrs}$ after transfection. CAT was assayed by ELISA and $\beta$-galactosidase by enzyme activity. The data represent relative average values (pg CAT/unit $\beta$-galactosidase/hr $+/$ $\mathrm{SE})$ from three independent experiments carried out in triplicates.

\section{NCU-GI mRNA is highly expressed in human liver, kidney and prostate}

The tissue specific expression of NCU-G1 in man was investigated at the mRNA-level. Most tissues tested were found to express NCU-G1 mRNA, however, it was most abundant in liver, kidney and prostate, with somewhat lower levels in placenta, ovary and adrenal. In contrast, expression was low in heart, lung, and skeletal muscle (data not shown). These results are corroborated by data reported on the SAGE-express web-site [31].

\section{Human NCU-GI acts as a co-activator for PPAR-alpha}

The presence of four NR-boxes in NCU-G1 prompted us to study its possible capacity to function as a co-regulator 
for nuclear receptors, here represented by PPAR-alpha, in transient transfections of S2 cells. The rationale for choosing PPAR was the identification of a number of potential peroxisome proliferator-activated receptor response elements (PPARE) in the human CRBP1 promoter region, using "MatInspector" from Genomatix [23]. In addition, PPAR-beta agonists have been reported to stimulate CRBP1 expression [15]. The ability of NCU-G1 to stimulate PPAR transcriptional activity may therefore be relevant to CRBP1 expression.

We chose to use a reporter gene construct expressing CAT under control of the rat acyl-CoA oxidase gene promoter [32], a well-known PPAR-alpha target gene [33]. We first determined the optimal level of PPAR-alpha to be coexpressed with NCU-G1 in S2 cells. As shown in figure 5A, expression of CAT was very low when PPAR-alpha was expressed only in the presence of the PPAR-alpha agonist WY14643, nor did expression of NCU-G1 lead to any increase in reporter gene expression. When co-expressed, however, a strong induction of reporter gene expression was observed, indicating that NCU-G1 may function as a co-activator for PPAR-alpha. Maximal induction using 150 ng of the PPAR-alpha expressing vector increased reporter gene expression by 11 -fold.

Interaction between co-activator NR-boxes and nuclear receptor AF-2 domains have been shown to require the ligand-induced conformational change of the latter [28]. Hence, we next sought to determine whether NCU-G1's ability to co-activate PPAR-alpha controlled reporter gene expression was ligand-dependent. Figure $5 \mathrm{~B}$ shows that this is indeed the case. When both PPAR-alpha and NCUG1 were expressed in the absence of the ligand, no CAT activity beyond the level directed by the pACO-CAT plasmid alone could be observed. However, addition of the agonistic ligand WY14643 increased CAT activity by approximately 11 -fold. This result demonstrates that NCU-G1's ability to co-activate PPAR-alpha requires ligand activation of the nuclear receptor.

We next sought to determine which, if indeed any, of the four NR-boxes in NCU-G1 is responsible for the observed co-activation. As shown in figure $5 \mathrm{C}$, mutation of $\mathrm{NR}$ boxes 2, 3, or 4 lowered the co-activating capacity of NCUG1 to approximately $50 \%$ of that observed with wild-type NCU-G1. Mutation of NR-box 1, however, completely abolished NCU-G1's ability to co-activate PPAR-alpha induced reporter gene expression, supporting our hypothesis that stimulation of PPAR-alpha controlled reporter gene expression by NCU-G1 is NR-box mediated. A similar effect was observed when all four NR-boxes were mutated. In summary, these results suggest that the mechanism of NCU-G1 co-activation of PPAR-alpha transcrip- tional activity requires an intact NR-box 1 and ligand mediated activation of the nuclear receptor.

\section{NCU-GI co-localises with PPAR-alpha in the nucleus}

Nuclear receptor co-activators may be divided into a primary and a secondary group where members of the former interact directly with nuclear receptors and the latter interact with members of the primary group [34]. In an effort to determine which of these groups NCU-G1 may belong to, its ability to interact with PPAR-alpha was studied in mammalian as well as yeast two-hybrid systems. No interaction was detected indicating that NCU-G1 is not a primary co-activator of this nuclear receptor (data not shown). The possibility of NCU-G1 being a secondary coactivator was analysed by confocal fluorescence microscopy. HeLa cells were transiently transfected with expression vectors for EGFP-tagged NCU-G1 and RFP-tagged PPAR-alpha. As shown in figure 6B RFP-PPAR-alpha is predominantly localised in the nucleus as expected. In contrast, as shown in figure 6A the fusion protein NCUG1-EGFP is mostly cytosolic. However, some NCU-G1EGFP was found in the nucleus at distinct spots which might indicate transport into the nucleus. Once within the nucleus, as shown in figure 6C, the few NCU-G1-EGFP spots co-localise with RFP-PPAR-alpha showing potential cellular interaction domains for NCU-G1 and PPARalpha.

\section{Discussion}

In this report, we describe the cloning and initial characterization of human NCU-G1. Sequence analysis detected no human homologues, however, NCU-G1 is highly conserved among species. Our experimental data show that NCU-G1 binds specifically to the FP1 element of the CRBP1 gene promoter and activates transcription from this promoter. Furthermore, NCU-G1 functions as a coactivator for PPAR-alpha directed reporter gene expression from the acyl-CoA oxidase promoter.

\section{NCU-GI as a transcription factor}

The identification of NCU-G1 as a DNA-binding protein suggested that it might be a transcription factor. In accordance with this notion we demonstrate specific binding to the FP1 element of the CRBP1 promoter. Further, NCUG1 is shown to mediate activation of transcription from the CRBP1 promoter. This transcriptional activity requires the presence of the FP1 element, suggesting that this DNA element actually is a target site for this potential transcription factor. NCU-G1 is a small protein without recognizable transcription activation domains or DNA-binding domains, two important regions of a transcription factor. Deletion of various exons or segments of NCU-G1 indicated that exon 2 and exon 6 are important for transcriptional activity. Since this protein has no substantial homology to any characterized protein, novel regions 
pMT-PPAR-alpha (300 ng) + pAc-NCU-G1 + ligand pMT-PPAR-alpha (200 ng) + pAc-NCU-G1 + ligand pMT-PPAR-alpha (150 ng) + pAc-NCU-G1 + ligand pMT-PPAR-alpha (100 ng) + pAc-NCU-G1 + ligand pMT-PPAR-alpha $(50 \mathrm{ng})+$ pAc-NCU-G1 + ligand pMT-PPAR-alpha $(5 \mathrm{ng})+$ pAc-NCU-G1 + ligand pAc-NCU-G1 + ligand pMT-PPAR-alpha (300 ng) + ligand pMT-PPAR-alpha (200 ng) + ligand pMT-PPAR-alpha (150 ng) + ligand PMT-PPAR-alpha (100 ng) + ligand pMT-PPAR-alpha $(50 \mathrm{ng})$ + ligand pMT-PPAR-alpha (5 ng)
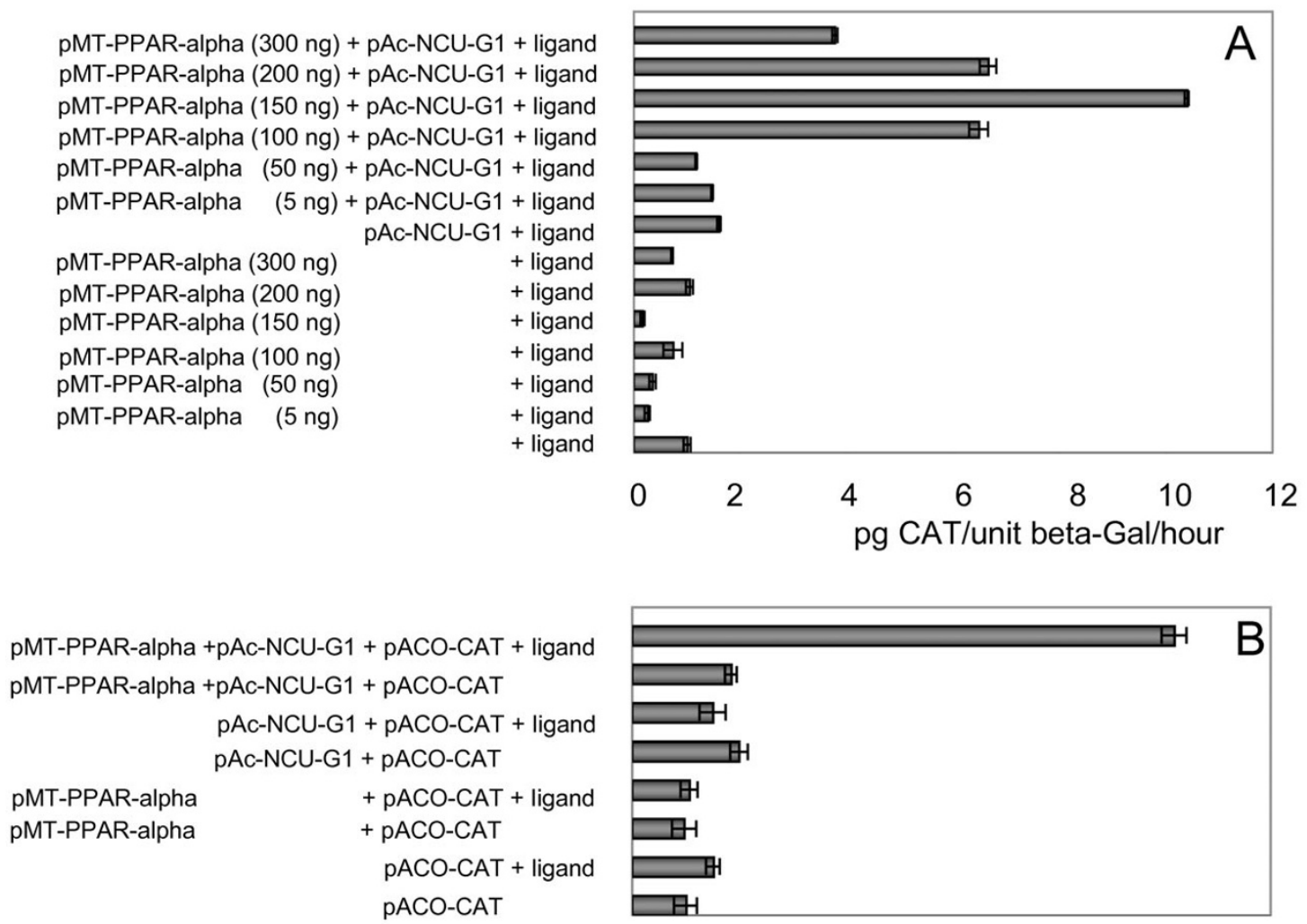

pMT-PPAR-alpha

pg CAT/unit beta-Gal/hour

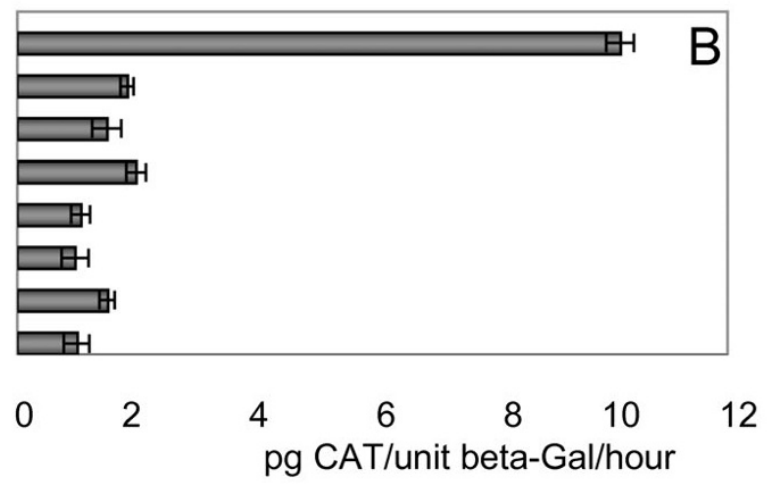

pAc-NCU-G1 (\#1-4mut) + pMT-PPAR-alpha
pAc-NCU-G1 (\#4mut) + pMT-PPAR-alpha
pAc-NCU-G1 (\#3 mut) + pMT-PPAR-alpha
pAc-NCU-G1 (\#2 mut) + pMT-PPAR-alpha
pAc-NCU-G1 (\#1 mut) + pMT-PPAR-alpha
pAc-NCU-G1 (wt) + pMT-PPAR-alpha
pAc-NCU-G1 (wt)
pMT-PPAR-alpha

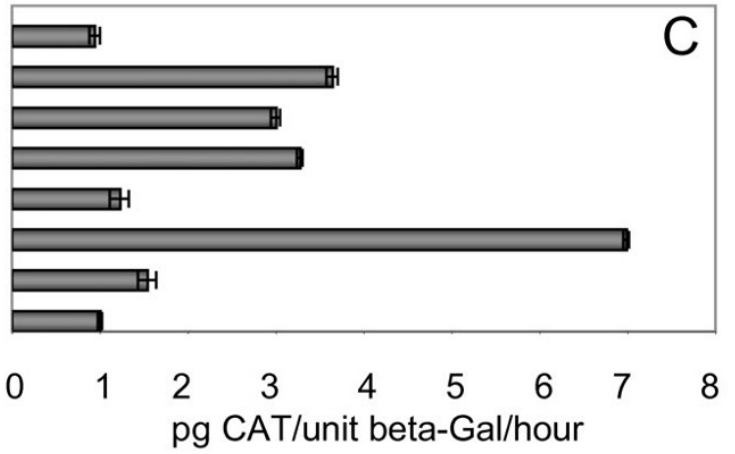

\section{Figure 5}

Human NCU-G I functions as a ligand dependent and NR-box dependent co-activator for PPAR-alpha in S2 cells. Panel A: S2 cells were transiently transfected with $250 \mathrm{ng}$ pAc5. IV5/His-LacZ, $350 \mathrm{ng}$ of pACO-CAT, and increasing amounts of pMT-hPPARalpha, in the presence or absence of $10 \mathrm{ng}$ of pAc-hNCU-GI. Twelve hrs after transfection WYI4643 was added to $20 \mu \mathrm{M}$. The cells were harvested $56 \mathrm{hrs}$ after transfection. CAT was assayed by ELISA and $\beta$-galactosidase by enzyme activity. The data represent relative average values (pg CAT/unit $\beta$-galactosidase/hr $+/$ - SE) from three independent experiments carried out in triplicates. Panel B: S2 cells were transiently transfected with $250 \mathrm{ng}$ PAc5.IV5/His-LacZ, 350 ng of PACO-CAT, together with pAc-hNCU-GI, pMT-hPPAR-alpha and WYI4643 as indicated. The cells were treated and presented as in panel A. Panel C: S2 cells were transiently transfected with $250 \mathrm{ng}$ pAc5.IV5/His-LacZ, $350 \mathrm{ng}$ of pACO-CAT, I50 ng PMT-hPPAR-alpha as indicated and $10 \mathrm{ng}$ of pAc-hNCU-GI, either wild-type or mutated as indicated in the figure. All cells were treated with $20 \mu \mathrm{M}$ WYI 4643. The cells were harvested and data presented as in panel $A$. 


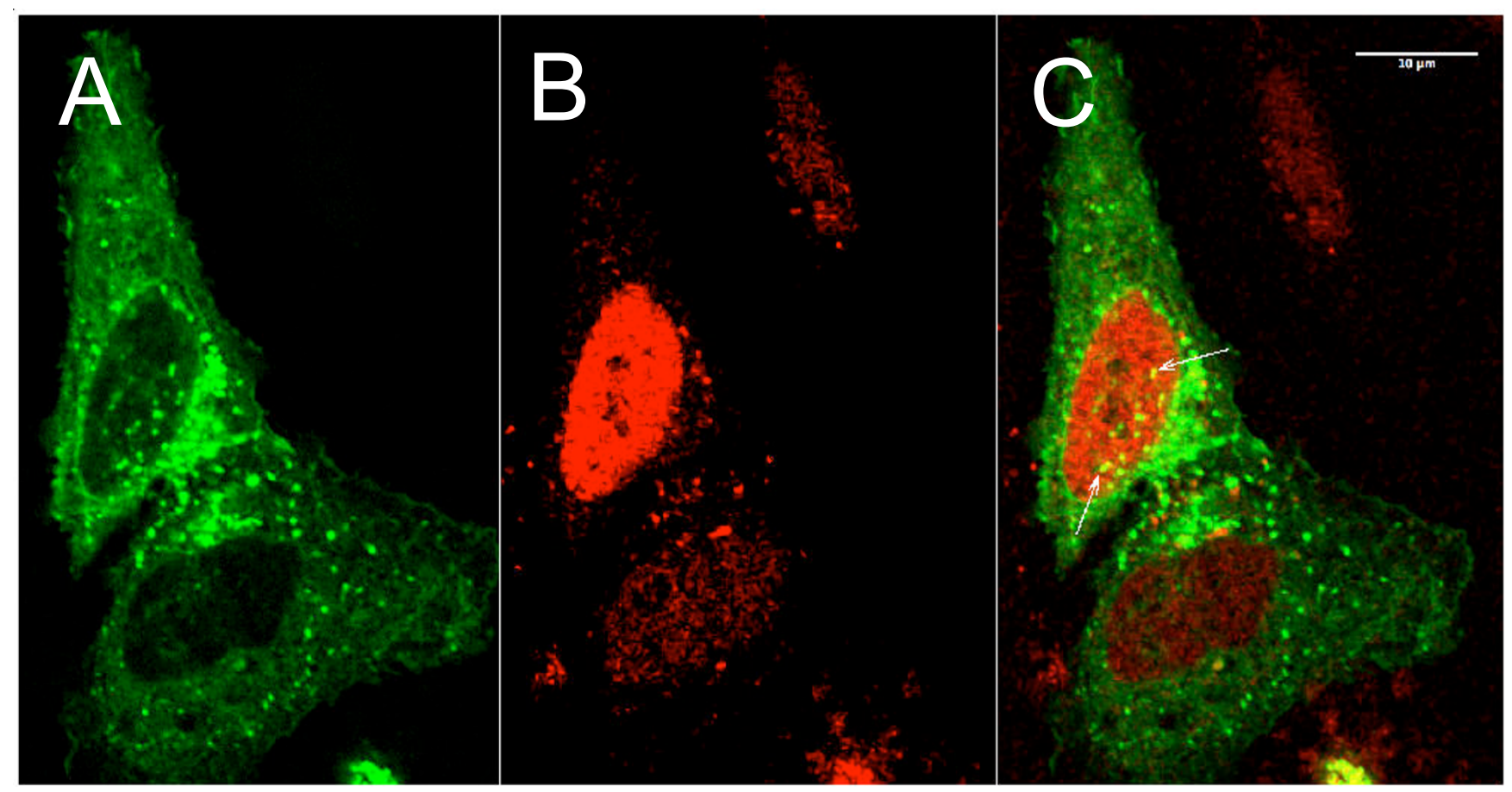

Figure 6

Human NCU-G I co-localises with PPAR-alpha in the nucleus. HeLa cells were transiently transfected with $0.8 \mu \mathrm{g}$ pNCU-G I-EGFP and $0.8 \mu \mathrm{g}$ PRFP-PPAR-alpha. Twenty hours after transfection WYI4643 was added to $2 \mu$ M. Six hours later the live cells were analysed by confocal fluorescence microscopy. Panel A: Green fluorescence showing subcellular localisation of NCU-GI-EGFP. Panel B: Red fluorescence showing subcellular localisation of RFP-PPAR-alpha. Panel C: Merged picture. Arrows show foci of co-localisation.

with other activities may still exist, however, their identification and characterization will be the subject of a future project.

\section{NCU-GI as a nuclear receptor coactivator}

The promoter region of the human CRBP1 gene has a number of potential PPAREs. Furthermore, PPAR-beta agonists have been reported to stimulate CRBP1 expression [15]. The ability of NCU-G1 to stimulate PPAR transcriptional activity may therefore be relevant to CRBP1 expression. Another example of proteins with transcriptional potential via both DNA-binding and protein-protein interaction is the homeodomain transcription factor Prox1 [35]. These types of proteins, the activity of which can be modulated via multiple pathways, appear to play important roles in various transcriptional networks.

The detection of four LXXLL motifs in the primary sequence suggested that NCU-G1 might function as a nuclear receptor co-regulator. This hypothesis was explored in transient transfections, where NCU-G1 was found to strongly stimulate transcription from the acyl CoA-oxidase promoter, a well-known PPAR-alpha target [33]. This stimulation was shown to be ligand-dependent and therefore requires the conformational change of the AF2 domain occuring as a consequence of ligand-binding. Site-directed mutagenesis of the NCU-G1 NR-boxes clearly demonstrated that NR-box 1 plays a predominant role in PPAR-alpha stimulation, since its mutation completely eliminated NCU-G1's ability to co-activate PPARalpha. NR-box preference in the interaction between nuclear receptor and co-activator has been described for other co-activators [36,37]. NR-box 1 is present in all available sequences from man to frog, indicating that is important for NCU-G1 function.

Based on the analysis of flanking sequences from both naturally interacting partners and phage-display assays, NR-boxes have been organized into four classes according to the amino acids at position -1 and -2 (the N-terminal $\mathrm{L}$ in the LXXLL motif is arbitrarily designated as +1 ). All classes have a hydrophobic amino acid at position -1, except for motifs that belong to class I which have a basic amino acid at that position. A proline is usually present at position -2 in class II motifs whereas class III motifs have a serine or a threonine at that position. A basic amino acid is usually found at position -2 in class IV motifs [36-38]. According to these rules we find that NR-box 1 most likely 
belongs to class II, although it has a leucine in both position -1 and -2 . In position -3 and -4 of this NR-box, a proline and a serine are present, respectively, making this a potential MAP-kinase target site, the phosphorylation of which may regulate interaction between NCU-G1 and nuclear receptors.

Mutation of any of the other three NR-boxes resulted in some reduction of reporter gene expression, hence it cannot be excluded that they too are of some importance to the NCU-G1 stimulated PPAR-alpha transcriptional activity. Alternatively, mutation of NR-boxes 2-4 may lead to conformational changes resulting in steric hindrance of the interaction between NR-box 1 and NCU-G1's protein partners.

Most co-regulators are large proteins with MW > $100 \mathrm{kDa}$. The $43.8 \mathrm{kDa}$ NCU-G1 is much smaller, yet it is far from being the smallest of the presently known co-regulators, some of which are as small as $16 \mathrm{kDa}$ [37]. Due to its small size and the fact that no domains with enzyme activity (such as histone deacetylase) or Q-rich domains mediating transcriptional activation have been identified in NCU-G1, we hypothesize that it may be a bridging factor. This notion fits with the presence of three potential SH3binding domains. In other proteins such as MNAR, PXXPmotifs have been shown to mediate interaction with the SH3-domains in Src-kinases or STAT-proteins [14]. NCUG1 may thus serve a function similar to that described for MNAR and PNRC which stabilize interaction between a Src-kinase and a nuclear receptor or transcription factor $[28,39]$. Such interaction between ER, c-Src and MNAR leads to phosphorylation of ER triggering stimulation of the transcriptional activation of ER target genes $[13,14,37,38]$.

NCU-G1 has two NES but no recognizable NLS, yet endogenous NCU-G1 is clearly localized in the nucleus of the three cell types tested (figure 2). Lacking an identifiable NLS sequence, it is presently unclear how NCU-G1 translocates from cytosol to the nucleus. The NLS motif remains a poorly defined amino acid sequence [40]. Indeed, a number of proteins lacking known NLS have been shown to enter the cell nucleus [41]. In NCU-G1's case two mechanisms of nuclear translocation may be considered. One mechanism is based on size. Since NCUG1 is a small protein with a molecular weight below the cut-off limit for free passage through nuclear pores, NCUG1 may enter by simple diffusion. Once inside the nucleus, NCU-G1 may interact with a nuclear NES-masking protein serving to hold NCU-G1 in this compartment as has been reported for p53 [42]. The other mechanism is the so-called "piggy-back" mechanism where masking of the NES is involved in nuclear translocation as described for BRCA1. Here the interacting partner, BARD1 mediates transport into the nucleus [41]. Interaction between a nuclear receptor and the NES overlapping NRboxes in NCU-G1 may also be regarded as a possible import mechanism for NCU-G1.

Based on NCU-G1's ability to co-activate PPAR-alpha we had anticipated direct interaction between the two proteins. Unfortunately, despite testing in several systems we failed to detect any direct interaction between the two proteins, indicating that NCU-G1 is not a primary co-activator for PPAR-alpha, but rather belongs to the group of secondary co-activators [34]. The results obtained by transient expression of the fluorescence tagged NCU-G1-EGFP and RFP-PPAR-alpha fusion proteins support this notion. In contrast to the localisation of endogenous NCU-G1 shown in figure 2, microscopy of ectopically expressed NCU-G1-EGFP showed extended localisation outside the nucleus. Fusion with EGFP leads to a molecular weight of approximately $70 \mathrm{kDa}$, well above the size limit for transfer to the nucleus by diffusion. Since NCU-G1 has no NLS this may explain why a large fraction of NCU-G1-EGFP is detected in the extranuclear compartment of the cell. The 3D-structure of NCU-G1 has not been solved, hence, we cannot exclude that fusion with EGFP disturbs the conformation of NCU-G1 regions important for subcellular trafficking. Although only a small part of expressed NCU-G1EGFP enters the nucleus, co-localisation with RFP-PPARalpha is observed. Thus co-localised NCU-G1-EGFP is in a position to act as co-activator for PPAR-alpha.

\section{Conclusion}

The present data suggest that NCU-G1 is a dual-function nuclear protein serving as a transcription factor as well as a nuclear receptor co-activator. Both these activities may contribute to controlling CRBP1 expression.

\section{Methods \\ Plasmids}

The pOTB7-hNCU-G1 from Origene (Rockville, MD, USA) was used as source of the ORF of NCU-G1. After digestion with EcoRI/Xho1 NCU-G1 was cloned into the Drosophila expression vector $\mathrm{pAc5.1/V5-His} \mathrm{vector} \mathrm{(Invit-}$ rogen, CA, USA), creating pAc-NCU-G1. To create pNCUG1-EGFP, the NCU-G1 ORF was excised by EcoR1/Age1 digestion from pOTB7-hNCU-G1 after modification of this plasmid by site-directed mutagenesis to insert an Age1 restriction site just before the stop codon of NCUG1. The fragment was fused in-frame with EGFP in EcoR1/ Age1 digested pEGFP-N1 (Clontech, CA, USA). The expression vector PRFP-PPAR-alpha was created by fusion in-frame of the Xho1/BamH1 digested mouse PPAR-alpha ORF, produced by PCR using the following primers: $5^{\prime}$ primer 5'-CTCCTCGAGCTATGGTGGACACAGAGA-3', 3'primer 5'-TATGGATCCTCAGTACATGTCTCTGTAGA-3' and pSG5-mPPAR-alpha as template, into a Xho1/BamH1 
digested pRFP-C1 vector (kindly donated by Dr. R. Tsien, Dept. of Pharmacology, University of California at San Diego, CA, USA [43].

\section{NR-box mutations}

Each NR-box LXXLL-sequence was mutated to LXXAA as described by the manufacturer using the QuikChange sitedirected mutagenesis kit from Stratagene (La Jolla, CA, USA). The following primers were used (complementary antisense-strand sequences are not shown): NR-box 1 mutagenesis 5'-CCCCTGCTCCTTTGGACTGCAGCTCTGTTTGCAGCCCCA-3' creating pAc-NCU-G1\#1mut, NRbox 2 mutagenesis 5'-GCCCCCTGCAGAACGCGGCTCATATACGGGCAGTGGGC-3' creating pAc-NCUG1\#2mut, NR-box 3 mutagenesis 5'-GTCTTCCAGTTGGACCAGGCAGCGTGGGGCTCCCTCCCA-3' creating pAc-NCU-G1\#3mut, NR-box 4 mutagenesis 5'GGCGGCTTGGTTCTGGCGGCGCACCACAAGAAG-

TACTCA-3' creating pAc-NCU-G1\#4mut. The pAc-NCUG1\#1.4mut was constructed by mutation of all four NRboxes.

\section{Deletion mutations}

All deletions were carried out as site-directed mutations according to the manufacturer using the QuikChange sitedirected mutagenesis kit from Stratagene (La Jolla, CA, USA). Complementary antisense-strand sequences are not shown. Primer 5'-GAATTGCGGCCGTATGGTGGCCACCAAC-3' was used to create pAc-NCU-G1 ( $\Delta$ aa1-81). Primer 5'-GACCCGCCAGGTGCTGCTTGAGTTTGAC-3' was used to create pAc-NCU-G1 ( $\Delta$ exon 2 ). Primer 5'CTTGTTTTTACCAGGTAAGGCCCGCTCTCTGG-3' was used to create pAc-NCU-G1 ( $\Delta$ exon 3-6). Primer 5'GGCCTTCAGGTAAGGCCCGCTCT-3' was used to create pAc-NCU-G1 ( $\Delta$ exon 4-6). Primer 5'-GCCGTCTTCCATAAGGCCCGCTCTCTGG-3' was used to create pAc-NCUG1 ( $\Delta$ exon 5-6). Primer 5'-CTGGGTGTGGGCTAAGGCCCGCTCTCTGG-3' was used to create pAc-NCU-G1 $(\Delta$ exon 6). Primer 5'-CCCCACTAGTCCTGCACCACAAGAAG-3' was used to create pAc-NCU-G1( $\triangle$ aa372-394). All mutations were verified by DNA sequencing. The LacZ expression plasmid pAc5/V5.1-His/LacZ was obtained from Invitrogen. The pACO-CAT vector was a gift from Dr. Jonathan Tugwood [32] and pMT-mPPAR-alpha vector was a gift from Dr. Hilde Nebb, University of Oslo. The reporter plasmids expressing CAT under the control of various fragments of the hCRBP1 promoter cloned into the pOCAT1 vector have been described [17]. The reporter plasmid phCRBP1-CAT was constructed by insertion of a Kpn1/Xho1-digested PCR amplified CRBP1 promoter ($567 /+104)$ fragment into the pCAT3 basic vector (Promega, Wi, USA). The CRBP1 promoter fragment was amplified using primers with the following sequences: forward primer 5'-CCGGTACCGAATTCCTGACCTCAGGTGATC-3', reverse primer 5'-GGCTCGAGTTCG-
GGGAGTGACTGGAGCCA-3'. The template was pA21EE, kindly donated by Magnus Nilsson [44].

\section{Cell cultures}

JEG3 cells (36-HTB; ATCC, Boras, Sweden) were grown in MEM with Earle's salts (BioWhitaker, Verviers, Belgium) containing $1 \mathrm{~g}$ glucose/liter and supplemented with Lglutamine (2 $\mathrm{mM})$, pyruvate $(1 \mathrm{mM})$, non-essential amino acids, $10 \%$ foetal calf serum (FCS) and antibiotics (penicillin 100 units/ml, streptomycin $100 \mu \mathrm{g} / \mathrm{ml}$ ). Flp-In 293 cells (Invitrogen, CA, USA) were grown in DMEM (high glucose) supplemented with L-glutamine (2 mM), $10 \%$ FCS and antibiotics (penicillin 50 units/ml, streptomycin $50 \mu \mathrm{g} / \mathrm{ml}, 100 \mu \mathrm{g}$ Zeocin/ml). RPE cells (hTERTRPE-1, Clontech, CA, USA) were grown in DMEM:F-12 supplemented with glutamine $(2 \mathrm{mM}), 10 \%$ FCS and antibiotics (penicillin 100 units/ml, streptomycin $100 \mu \mathrm{g} /$ $\mathrm{ml})$. HeLa cells were grown in the same medium as Flp-In 293 cells but without Zeocin. All mammalian cells were grown at $37^{\circ} \mathrm{C}$ in a humidified atmosphere under $5 \%$ $\mathrm{CO}_{2}$. Drosophila Schneider S2 cells (Drosophila Schneider line 2, \# CRL-1963, ATCC) were grown in TC100 medium (PAA Laboratories, Coelbe, Germany) supplemented with 10\% heat inactivated FCS (PAA laboratories, \#A11-081, insect cell pretested), and antibiotics (penicillin 100 units $/ \mathrm{ml}$, streptomycin $100 \mu \mathrm{g} / \mathrm{ml}$, and fungizone $0.25 \mu \mathrm{g} / \mathrm{ml}$ ). The cells were grown at $26^{\circ} \mathrm{C}$ without $\mathrm{CO}_{2}$.

\section{Electrophoretic mobility shift assay}

Double-stranded oligonucleotides representing the FP1 element in the CRBP1 promoter were labelled with $\left[{ }^{32} \mathrm{P}\right] \gamma \mathrm{ATP}$. For each reaction $3 \times 10^{4} \mathrm{cpm}$ labelled probe was incubated with $2 \mu \mathrm{g}$ GST-NCU-G1 in the presence or absence of competing oligonucleotides as described [17]. Oligonucleotide sequences were the following (only the upper strand is shown): FP1: 5'-GATCCGCCCGCTTGTGGCCAACTGGCTCCAGTCAC-3', AP1: 5'-CGCTTGATGACTCAGCCGGAA-3', Sp1: 5'GATCATATCTGCGGGGCGGGGCAGACACAG-3', NF1: 5'-GATCTTATTTTGGATTGAAGCCAATATGAG-3'.

\section{Production of GST-NCU-GI fusion protein}

The ORF of NCU-G1 was excised from pOTB7-hNCU-G1 with EcoRI and Xho1 and fused in-frame with glutathione-S-transferase in the pGEX-5X-3 vector (GE Healthcare Bio-Sciences, Uppsala, Sweden). The fusion-protein was expressed in E. coli BL21(DE3) and purified according to the manufacturer's protocol (Invitrogen, CA, USA).

\section{Western analysis}

Cells were homogenized and fractionated into nuclear and cytosolic fractions by the method of Dignam [45]. Twenty micrograms proteins were fractionated on a $10 \%$ SDS-polyacrylamide gel (29:1) and electro-transferred to a PVDF membrane (Bio-Rad, Hercules, USA). The mem- 
brane was blocked for 2 hrs in phosphate buffered saline containing 5\% non-fat milk (PBSM). Primary antibody incubation for $2 \mathrm{hrs}$ at $25^{\circ} \mathrm{C}$ was carried out with the NCU-G1 antiserum diluted 1:1000 in PBSM containing $0.1 \%$ Tween 20 (PBSMT). Membranes were washed in PBS containing $0.1 \%$ Tween $203 \times 5$ min., plus $3 \times 15$ min. with shaking. The secondary antibody (peroxidasecoupled goat-antirabbit IgG, GE Healthcare Biosciences, Uppsala, Sweden) was diluted 1:3000 in PBSMT and incubated with the membrane for $2 \mathrm{hrs}$ at $25^{\circ} \mathrm{C}$. Membranes were washed as described above and subjected to a final wash with PBS. Protein bands were visualized using Supersignal West Pico reagents from Pierce (Rochford, USA). The membranes were stripped by incubation for 5 min in $0.2 \mathrm{M} \mathrm{NaOH}$ followed by several rinses in PBS before further analysis.

\section{Northern hybridization}

Hybridization was carried out on a human multi-tissue mRNA filter (Clontech, CA, USA) using a ${ }^{32} \mathrm{P}$-labeled NCU-G1 cDNA and beta-actin cDNA as a probes, according the manufacturer's instructions. NCU-G1 mRNA expression levels for each tissue were normalized to the expression levels of beta-actin and quantified by relative comparison of the intensity of 32P-labeled NCU-G1 cDNA.

\section{One-hybrid cloning}

The MATCHMAKER One-hybrid System (Clontech, CA, USA) was used to clone NCU-G1. The following oligonucleotide sequence was used as bait: CGCTTGTTTTTTTCTGGCTC. This sequence is a modified version of the FP1 element from the hCRBP-1 gene promoter [17] from which the Sp1 binding site has been truncated and the NF1 binding site mutated to avoid interference from these transcription factors. A triplicate version of the oligonucleotide (CGCTTGTTTTTTTCTGGCTCCGCTTGTTTTTTTCTGGCTCCGCTTG-TTTTTTTCTGGCTC) was inserted into the EcoR1-Sac1 site upstream of the HIS3 reporter gene in the pHISi-vector. A MATCHMAKER cDNA library from human placenta (Clontech, CA, USA) was used for screening. Three positive clones were obtained one of which contained an ORF of $1221 \mathrm{bp}$. Sequencing was carried out by GATC (Konstanz, Germany) using the Sanger dideoxy method.

\section{Transfections}

For transient transfections of S2 cells, $4 \times 10^{5}$ cells were plated in $9 \mathrm{~cm}^{2}$ wells (6-well plates) in $2 \mathrm{ml}$ complete medium. Transfection was carried out the following day using Fugene 6 (Roche, Mannheim, Germany). Each tissue culture well received a total of $1 \mu \mathrm{g}$ DNA, comprising 250 ng pAc5.1-LacZ (Invitrogen, CA, USA), 350 ng reporter vector either pACO-CAT, phCRBP1-CAT or phCRBP1OCAT, 5-300 ng pMT-PPAR-alpha and $10 \mathrm{ng}$ of
pAc-NCU-G1 wild-type or mutated/truncated. When expressing PPAR-alpha, $\mathrm{CuSO}_{4}$ was added to $5 \mu \mathrm{M}$ at the time of transfection to activate expression from the metallothionine promoter. Twelve hours after transfection, the PPAR-alpha agonist WY14643 (Sigma-Aldrich, St. Louis, USA) was added to $20 \mu \mathrm{M}$. Fifty-six hours after transfection the cells were harvested in $1 \times$ lysis buffer from the CAT ELISA kit (Roche, Mannheim, Germany). Expression of CAT was determined using this kit according to the manufacturer's instructions. The transfection efficiency was determined by measuring the $\gamma$-galactosidase activity. Reporter gene expression was calculated as pg CAT/unit $\beta$ galactosidase/hour and presented as relative expression levels compared to controls which were assigned the value 1.0. The data presented are the mean values of three separate transfections carried out in triplicates.

For confocal fluorescence microscopy HeLa cells were plated in microwell dishes for microscopy (Mattek, MA, USA) and transfected the following day using Lipofectamine according to the manufacturer's protocol (Invitrogen, CA, USA). Each tissue culture plate received 0.8 $\mu \mathrm{g}$ of pNCU-G1-EGFP and $0.8 \mu \mathrm{g}$ of pRFP-PPAR-alpha. Microscopy was carried out 20 hours later.

\section{Antibodies}

A peptide comprising the 15 C-terminal amino acids of hNCU-G1 was chosen for antibody production. Peptide sequence: LLLHHKKYSEYQSIN. Peptide synthesis, coupling of the peptide to KLH (keyhole limpet hemocyanin), injection into rabbits and bleeding was carried out by MedProbe/Eurogentec (Oslo, Norway). The antisera were tested in our laboratory. Preimmune serum did not detect any proteins in a Western analysis of crude nuclear extracts from transfected S2 cells transiently expressing NCU-G1. The antiserum detected a protein of approximately $45 \mathrm{kDa}$. The polyclonal antibodies directed against AP1, Sp1 and NF1 were purchased from Santa Cruz (Santa Cruz, CA, USA).

\section{Yeast two-hybrid interaction}

Interaction between PPAR-alpha and NCU-G1 was assayed using Clontech's Matchmaker GAL4 Two-Hybrid System. Full-length mPPAR-alpha was PCR-amplifed using the following primers: forward primer 5'TCGACCTTCCCGGGGATCCTGTCTCGAGAAATGGTGGACACGGAAAGCCCA-3', reverse primer 5'-ACTGAGTCGTCGACGCGGCCGCTTACTAGTACATGTCCCT GTAGATCTCCTG-3' and pMT-mPPAR-alpha as template. PPAR-alpha was digested with BamH1/Sal1 and fused inframe with the GAL4 activation domain in BamH1/Xho1 digested pGADT7 creating pGADT7-PPAR-alpha. Fulllength hNCU-G1 was PCR-amplified using the following primers: forward primer 5'-TCGACCTGAATTCATCCCGGGATCTCGAGTTATGCGCGGCTCTGTGGAG-3', reverse 
primer 5'-ACTGAGTCGTCGACGCGGCCGCTTACTAATTTATGGACTGGTACTCTGAGTA-3' and pOTB7-hNCU-G1 as template. NCU-G1 was fused in-frame with the GAL4 binding domain in pGBKT7 after digestion with EcoRI/ Sal1 creating pGBKT7-NCU-G1. The authenticity of PPAR-alpha, NCU-G1 and their fusion sites were verified by sequencing. The yeast strains Y187-alpha transformed with pGADT7-PPAR-alpha and AH109a transformed with pGBKT7-NCU-G1 were mated by $\mathrm{o} / \mathrm{n}$ co-incubation in synthetic complete medium (Clontech) lacking Leu and Trp before plating onto agar dishes of the same medium. Positive clones were transferred to agar dishes containing PPAR-alpha ligand (WY14643, 200 nM) but lacking Leu, Trp and His to test interaction between PPAR-alpha and NCU-G1. Y187-alpha transformed with pGADT7-T and AH109a transformed with pGBKT7-53 were used for positive controls. Y187-alpha transformed with PGADT7 and AH109a transformed with pGBKT7 were used for negative controls.

\section{Confocal fluorescence microscopy}

Prior to imaging, the cell medium was changed to DMEM without phenol red and sodium carbonate (BioWhitaker, Verviers, Belgium). Image acquisition was performed on an Olympus Fluoview 1000 at $37^{\circ} \mathrm{C}$ with an Olympus PlanApo 60×/1.42 oil objective (Olympus Europa, Hamburg, Germany). More than 200 live cells from 5 transfections were analysed, selecting a wide variety of expression levels and the co-localisation conclusion is based on this.

\section{List of abbreviations}

AF2 activation function domain 2

AP1 Activating protein 1

Bp1 binding protein 1

Bp2 binding protein 2

cAMP adenosine 3',5'-cyclic monophosphate

CAT chloramphenicol acetyl-transferase

CRBP1 cellular retinol-binding protein 1

CRM1 exportin chromosome region maintenance 1

EGFP enhanced green fluorescent protein

FP1 footprint 1

GST glutathione-S-transferase

NCU-G1 kidney predominant protein
NES nuclear export signal

NF1 nuclear factor 1

NLS nuclear localization signal

NR nuclear receptor

PPAR peroxisome proliferators-activated receptor

PVDF polyvinylidene difluoride

RAR retinoid acid receptor

RBP retinol-binding protein

RFP red fluorescent protein

RXR retinoid $\times$ receptor

SH3 Src-homology 3

Sp1 specificity protein 1

\section{Authors' contributions}

KS cloned and sequenced hNCU-G1. He analysed the mRNA levels of NCU-G1 in human tissues, interaction between PPAR-alpha and NCU-G1 in a mammalian twohybrid system and contributed to writing of the manuscript. MB carried out plasmid constructions and transient transfections of S2 cells. FS and OB analysed interaction between NCU-G1 and PPAR-alpha by confocal fluorescence microscopy. AK analysed subcellular localisation of NCU-G1 by Western. CK and VM analysed interaction between PPAR-alpha and NCU-G1 in yeast. SG initially identified Bp1 and Bp2 and contributed to writing of the manuscript. WE designed the project, wrote the manuscript, carried out in silico analysis of NCU-G1 and analysed NCU-G1 binding to DNA in EMSA. All authors have read and approved the final manuscript.

\section{Acknowledgements}

This study was supported by the Norwegian Cancer Society. We thank Martin Enger for helping with sequence analysis and Hilde Letnes for expert technical assistance.

\section{References}

I. Mangelsdorf DJ: Vitamin A receptors. Nutr $\operatorname{Rev} 1994$, 52(2 Pt 2):S32-44.

2. Tsai MJ, O'Malley BW: Molecular mechanisms of action of steroid/thyroid receptor superfamily members. Annu Rev Biochem 1994, 63:45I-486.

3. Altucci L, Gronemeyer H: The promise of retinoids to fight against cancer. Nat Rev Cancer 200I, I(3): I8I-193.

4. Farias EF, Marzan C, Mira-y-Lopez R: Cellular retinol-binding protein-I inhibits PI3K/Akt signaling through a retinoic acid receptor-dependent mechanism that regulates p85-pII0 heterodimerization. Oncogene 2005, 24(9): 1598-1606. 
5. Cretkovic D, Williams SJ, Hamilton TC: Loss of cellular retinolbinding protein I gene expression in microdissected human ovarian cancer. Clin Cancer Res 2003, 9(3): I013-1020.

6. Bistulfi G, Pozzi S, Ren M, Rossetti S, Sacchi N: A repressive epigenetic domino effect confers susceptibility to breast epithelial cell transformation: implications for predicting breast cancer risk. Cancer Res 2006, 66(2I):10308-103/4

7. Kurlandsky SB, Gamble MV, Ramakrishnan R, Blaner WS: Plasma delivery of retinoic acid to tissues in the rat. J Biol Chem 1995, 270(30): I 7850-I 7857.

8. Ross AC: Cellular metabolism and activation of retinoids: roles of cellular retinoid-binding proteins. Faseb J 1993, 7(2):317-327.

9. Napoli JL: A gene knockout corroborates the integral function of cellular retinol-binding protein in retinoid metabolism. Nutr Rev 2000, 58(8):230-236.

10. Ghyselinck NB, Bavik C, Sapin V, Mark M, Bonnier D, Hindelang C, Dierich A, Nilsson CB, Hakansson H, Sauvant P, Azaïs-Braesco V, Frasson M, Picaud S, Chambon P: Cellular retinol-binding protein I is essential for vitamin A homeostasis. Embo J 1999, I 8( I 8):4903-49|4.

II. Rush MG, Ul-Haq R, Chytil F: Opposing effects of retinoic acid and dexamethasone on cellular retinol-binding protein ribonucleic acid levels in the rat. Endocrinology I99|, I29(2):705-709.

12. Okuno M, Caraveo VE, Goodman DS, Blaner WS: Regulation of adipocyte gene expression by retinoic acid and hormones: effects on the gene encoding cellular retinol-binding protein. J Lipid Res 1995, 36(I): 137-147.

13. Eskild W, Oyen O, Beebe S, Jahnsen T, Hansson V: Regulation of mRNA levels for cellular retinol binding protein in rat Sertoli cells by cyclic AMP and retinol. Biochem Biophys Res Commun 1988, I52(3): I504-1510.

14. Tannous-Khuri L, Talmage DA: Decreased cellular retinol-binding protein expression coincides with the loss of retino responsiveness in rat cervical epithelial cells. Exp Cell Res 1997, 230(I):38-44.

15. Hellemans K, Rombouts K, Quartier E, Dittie AS, Knorr A, Michalik L, Rogiers V, Schuit F, Wahli W, Geerts A: PPARbeta regulates vitamin A metabolism-related gene expression in hepatic stellate cells undergoing activation. I Lipid Res 2003, 44(2):280-295.

16. Kroepelien CF, Knutsen HK, Haugen TB, Hansson V, Eskild W: Serum factors induce messenger ribonucleic acid levels for cellular retinol-binding protein in rat Sertoli cells. Endocrinology 1993, I32(3):968-974.

17. Eskild W, Simard J, Hansson V, Guerin SL: Binding of a member of the NFI family of transcription factors to two distinct cisacting elements in the promoter and 5 '-flanking region of the human cellular retinol binding protein I gene. Mol Endocrinol 1994, 8(6):732-745.

18. Leclerc S, Eskild W, Guerin SL: The rat growth hormone and human cellular retinol binding protein I genes share homologous NFI-like binding sites that exert either positive or negative influences on gene expression in vitro. DNA Cell Biol 1997, 16(8):95I-967.

19. Ossipow V, Laemmli UK, Schibler U: A simple method to renature DNA-binding proteins separated by SDS-polyacrylamide gel electrophoresis. Nucleic Acids Res 1993 2I(25):6040-604I.

20. Kawamura T, Kuroda N, Kimura Y, Lazoura E, Okada N, Okada H: cDNA of a novel mRNA expressed predominantly in mouse kidney. Biochem Genet 200I, 39(I-2):33-42.

21. Genbank [http://www.ncbi.nlm.nih.gov]

22. JustBio [http://www.justbio.com]

23. Genomatix [http://www.genomatix.de]

24. The Eukaryotic Linear Motif Resource [http:// www.elm.eu.org]

25. Savkur RS, Burris TP: The coactivator LXXLL nuclear receptor recognition motif. J Pept Res 2004, 63(3):207-2I 2.

26. Heery DM, Kalkhoven E, Hoare S, Parker MG: A signature motif in transcriptional co-activators mediates binding to nuclear receptors. Nature 1997, 387(6634):733-736.

27. Cesareni G, Panni S, Nardelli G, Castagnoli L: Can we infer peptide recognition specificity mediated by SH3 domains? FEBS Lett 2002, 5 I 3(I):38-44.
28. Wong CW, McNally C, Nickbarg E, Komm BS, Cheskis B]: Estrogen receptor-interacting protein that modulates its nongenomic activity-crosstalk with Src/Erk phosphorylation cascade. Proc Natl Acad Sci USA 2002, 99(23): $14783-14788$.

29. Henderson $B R$, Eleftheriou A: A comparison of the activity, sequence specificity, and CRMI-dependence of different nuclear export signals. Exp Cell Res 2000, 256(I):213-224.

30. Suske G: Transient transfection of Schneider cells in the study of transcription factors. Methods Mol Biol 2000, I30: I75-I87.

31. SAGEexpress [http://genome.ewha.ac.kr/ECgene/SAGEexpress]

32. Tugwood JD, Issemann I, Anderson RG, Bundell KR, McPheat WL, Green S: The mouse peroxisome proliferator activated receptor recognizes a response element in the 5 ' flanking sequence of the rat acyl CoA oxidase gene. Embo J 1992 , I I (2):433-439.

33. Lee MJ, Gee P, Beard SE: Detection of peroxisome proliferators using a reporter construct derived from the rat acyl-CoA oxidase promoter in the rat liver cell line H-4-II-E. Cancer Res 1997, 57(8): 1575-1579.

34. Yu S, Reddy JK: Transcription coactivators for peroxisome proliferator-activated receptors. Biochimica et Biophysica Acta 2007, I77 I(8):936-95I.

35. Steffensen KR, Holter E, Bavner A, Nilsson M, Pelto-Huikko M, Tomarev S, Treuter E: Functional conservation of interactions between a homeodomain cofactor and a mammalian FTZFI homologue. EMBO Rep 2004, 5(6):6|3-619.

36. Chang C, Norris JD, Gron H, Paige LA, Hamilton PT, Kenan DJ, Fowlkes D, McDonnell DP: Dissection of the LXXLL nuclear receptor-coactivator interaction motif using combinatorial peptide libraries: discovery of peptide antagonists of estrogen receptors alpha and beta. Mol Cell Biol 1999, 19(1 2):8226-8239.

37. Mclnerney EM, Rose DW, Flynn SE, Westin S, Mullen TM, Krones A, Inostroza J, Torchia J, Nolte RT, Assa-Munt N, Milburn MV, Glass CK, Rosenfeld MG: Determinants of coactivator LXXLL motif specificity in nuclear receptor transcriptional activation. Genes Dev 1998, I 2(21):3357-3368.

38. Bramlett KS, Burris TP: Effects of selective estrogen receptor modulators (SERMs) on coactivator nuclear receptor (NR) box binding to estrogen receptors. Mol Genet Metab 2002, 76(3):225-233

39. Zhou $D$, Chen $S$ : PNRC2 is a 16 kDa coactivator that interacts with nuclear receptors through an SH3-binding motif. Nucleic Acids Res 200I, 29(19):3939-3948.

40. Chan CK, Jans DA: Using nuclear targeting signals to enhance non-viral gene transfer. Immunol Cell Biol 2002, 80(2): I I9-130.

4I. Fabbro M, Rodriguez JA, Baer R, Henderson BR: BARDI induces BRCAI intranuclear foci formation by increasing RING. dependent BRCAI nuclear import and inhibiting BRCAI nuclear export. J Biol Chem 2002, 277(24):21315-2/324.

42. Stommel JM, Marchenko ND, Jimenez GS, Moll UM, Hope TJ, Wahl GM: A leucine-rich nuclear export signal in the p53 tetramerization domain: regulation of subcellular localization and p53 activity by NES masking. Embo J 1999, 18(6): 1660-1672.

43. Campbell RE, Tour O, Palmer AE, Steinbach PA, Baird GS, Zacharias DA, Tsien RY: A monomeric red fluorescent protein. Proc Natl Acad Sci USA 2002, 99( I 2):7877-7882

44. Nilsson MH, Spurr NK, Lundvall J, Rask L, Peterson PA: Human cellular retinol-binding protein gene organization and chromosomal location. Eur J Biochem 1988, I73(I):35-44.

45. Dignam JD, Lebovitz RM, Roeder RG: Accurate transcription initiation by RNA polymerase II in a soluble extract from isolated mammalian nuclei. Nucleic Acids Res 1983, I I(5): | $475-1489$ 